\title{
LOS MECANISMOS Y NORMAS DE PROTECCIÓN EN LAS RELACIONES LABORALES
}

Julio Ismael Camacho Solís.

Julio_camacho@hotmail.com

Recebido em 27/06/2012

Aprovado em 28/06/2013

\begin{abstract}
RESUMEN
En el derecho laboral el Estado se involucra en las relaciones privadas de trabajo protegiendo a la parte más débil de esa relación. Precisamente en atención a tal tutela la ley laboral vigente recoge y establece una serie de manifestaciones concretas, elevadas a la categoría de principios generales por la doctrina, que se encuentran entrelazadas entre si por una genérica función tutelar del trabajador. Hoy pareciera apropiado señalar que esa tutela que se reconoce a los principios generales del derecho laboral, obedecen también al apuntalamiento de un modelo de desarrollo que propugna por relaciones laborales definidas y controladas en contenido y ejecución por el Estado.
\end{abstract}

PALABRAS LLAVES

Derecho social, estabilidad laboral, normas protectoras, derecho colectivo, integridad social. 


\title{
THE MECHANISMS AND PROTECTION RULES IN LABOURS RELATIONSHIPS
}

\author{
Julio Ismael Camacho Solís.
}

\author{
Abstract \\ In labour law the State gets involved in private labour \\ relations protecting the weakest of the relationship \\ part. Precisely in response to such protection, \\ the existing labour law collects and establishes a \\ series of practical demonstrations, elevated to the \\ category of general principles by the doctrine, which \\ are intertwined each other to protect the worker by \\ a generic function. Today it seems appropriate to \\ point out that guardianship that it recognizes the \\ General principles of labour law, are also due to \\ the underpinning of a development model which \\ advocates for work defined and controlled in content \\ and execution by the State.
}

Keywords

Social law, employment stability, protective regulations, collective right, social integrity. 
Sumario:

Introducción

1. El principio protector del Derecho del Trabajo

2. El principio de la irrenunciabilidad

3. El principio de continuidad de la relación

4. Principio de la condición más beneficiosa

5. Principio de igualdad de trato

6. El principio de beneficio en caso de duda

7. Principio de la Primacía de la Realidad

8. Principio de la Buena Fe

9. Principio de la Razonabilidad

10. Principio de gratuidad

11. Los efectos del modelo económico actual y la necesaria revalorización de los principios del derecho laboral y sus normas protectoras

12. La protección en contra de la discriminación laboral

13. La protección social internacional en contra de la discriminación en el derecho del trabajo

14. Trascendencia del tema de la igualdad de género

15. La protección de los derechos sindicales

16. Autonomía Sindical -

17. Los principios del derecho procesal del trabajo en la legislación mexicana

18. Derecho a la seguridad social. 


\section{INTRODUCCIÓN}

Como entender al derecho del trabajo sin considerar que de manera conjunta se da la integración de "normas generales" que subyacen o informan todos los ordenamientos laborales y que cuentan en muchos casos también con un origen derivado de las normas de rango constitucional. Estos principios generales, se encuentran en la base de todo el derecho laboral Como los principales pueden citarse el principio protector y sus reglas, el principio de la irrenunciabilidad y e principio de la continuidad de la relación; junto a ellos, coexisten también el principio de la condición más beneficiosa, el de igualdad de trato, de la gratuidad, de razonabilidad y el principio a favor de la duda, entre otros.

Estos principios, al igual que los generales del derecho, poseen tres funciones netamente diferenciadas: a) función informativa, ya que sirven de base e informan al legislador; b) función interpretativa, porque deben ayudar al intérprete de la norma para una correcta aplicación, en especial a las autoridades del trabajo, que son los encargados de aplicarla y c) función normativa, no sólo porque en ausencia de la norma el principio adquiere significativa importancia supliendo a la norma, sino además porque podrá estar expresado normativamente en un cuerpo legal.

"El trabajo del hombre es necesario a la sociedad. La historia y la vida social están construidas sobre el trabajo de los hombres y la humanidad necesita, en su futuro, de ese mismo trabajo" "El trabajador requiere protección. Como el trabajador se encuentra bajo la subordinación del patrón y, en la mayoría de los casos, en una situación de dependencia económica, requiere ser protegido para eliminar los inconvenientes de ese sometimiento personal y económico" "La realidad social es diversa y cambiante. La diversidad y cambio de la materia social, así como el progreso de las ciencias respecto al conocimiento del hombre y de la sociedad, afectan la realización de la justicia y determina que la política jurídica - laboral establezca normas e instituciones con contenidos diferentes de un lugar a otro o de una época a otra.

\section{El principio protector del Derecho del Trabajo}

Un reconocimiento prácticamente unánime establece que la ley laboral tiene como un verdadero principio general la protección del trabajador. Semejante principio, fundamentado en la génesis misma de las leyes relacionadas con la misma materia, ante ello se justifica por si sola la intervención estatal en la emisión de las normas, en la vigilancia de su cumplimiento efectivo, y en la aplicación especifica. Sin embargo, un objetivo adicional también importante, y no expresamente declarado 
parece ser, como se suponía en el cambiante mundo del trabajo, el mantenimiento de un modelo de desarrollo económico que presuponía un mercado de trabajo cautivo y estrictamente regulado.

Respecto a ello cabe señalar que efectivamente la ley laboral tiende a la protección o tutela de la parte más débil de las relaciones laborales. Este contenido, denominado por la doctrina como el principio protector del derecho laboral, contiene como bien se sabe reglas especificas que lo implementan la interpretación más favorable al trabajador (In dubio pro operario), la regla de la condición más beneficiosa, y la regla de la norma más favorable. La importancia del principio protector es tal, que en realidad se le llega a ubicar por algunos como diseminados en todo el contenido de la ley laboral; trasciende por así decirlo, un ámbito restringido.

En todo caso, se trata de reglas establecidas en protección y/o tutela del trabajador pero también en función de las definiciones efectuadas respecto al comportamiento a que se obliga a los actores del mercado de trabajo, considerando que uno de ellos - el trabajador - es la parte más débil. Atendiendo a esa amplitud, una manifestación concreta del principio podemos encontrarlas incluso en las disposiciones constitucionales que establecen la obligación del Estado de tutelar los derechos de los trabajadores. Este principio además busca armonizar las relaciones entre el capital y el trabajo y se funda en principios que tienden al mejoramiento de las condiciones de vida de los trabajadores y se desarrolla también en una función tutelar o protectora todas las disposiciones laborales relativas a derechos básicos del trabajador en materia de jornadas, descansos, salarios,vacaciones, dias de descanso,capacitación y adiestramiento y aquellas normas que establecen prohibiciones u obligaciones, destinadas a regular la conducta de las partes y evitar prejuicios al trabajador.

Por ello la legislación mexicana contempla la protección fundamental a lo trabajadores de manera indistinta de la siguiente manera a considerar destacando:

Artículo $2^{\circ}$. - Las normas de trabajo tienden a conseguir el equilibrio y la justicia social en las relaciones entre trabajadores y patrones.

Artículo $3^{\circ}$. - El trabajo es un derecho y un deber sociales. No es artículo de comercio, exige respeto para las libertades y dignidad de quien lo presta y debe efectuarse en condiciones que aseguren la vida, la salud y un nivel económico decoroso para el trabajador y su familia.

No podrán establecerse distinciones entre los trabajadores por motivo de raza, sexo, edad, credo religioso, doctrina política o condición social.

Asimismo, es de interés social promover y vigilar la capacitación y el adiestramiento de los trabajadores. 


\section{El principio de la irrenunciabilidad:}

Este principio de define como "la imposibilidad jurídica de privarse voluntariamente de una o más ventajas consentidas por el derecho laboral en beneficio propio".

En algunas cosas se establece en el ámbito constitucional como parte del contenido laboral, una disposición expresa en cuanto a que los derechos consagrados a favor de los trabajadores son irrenunciables; mientras que en otros, como se verá se le enuncia, también expresamente, en la propia ley laboral". ${ }^{1}$

Estos principios valen para todo el derecho del trabajo, sean estos individuales y colectivos, normas sustantivas y normas adjetivas para su aplicación, tomando en cuenta que el derecho surge como una consecuencia de una desigualdad: la derivada de la inferioridad económica del trabajador. Ese es el origen de la cuestión social y del derecho del trabajo.

Destacando para ello lo que contempla la Ley Federal del Trabajo en artículos diversos:

Artículo $5^{\circ}$. - Las disposiciones de esta Ley son de orden público por lo que no producirá efecto legal, ni impedirá el goce y el ejercicio de los derechos, sea escrita o verbal, la estipulación que establezca:

I. Trabajos para niños menores de catorce años;

II. Una jornada mayor que la permitida por esta Ley;

III. Una jornada inhumana por lo notoriamente excesiva, dada la índole del trabajo, a juicio de la Junta de Conciliación y Arbitraje;

IV. Horas extraordinarias de trabajo para los menores de dieciséis años

V. Un salario inferior al mínimo;

VI. Un salario que no sea remunerador, a juicio de la Junta de Conciliación y Arbitraje;

VII. Un plazo mayor de una semana para el pago de los salarios a los obreros;

VIII. Un lugar de recreo, fonda, cantina, café, taberna o tienda, para efectuar el pago de los salarios, siempre que no se trate de trabajadores de esos establecimientos;

PIÁ RODRIGUEZ, Américo. Los principios del derecho del trabajo. 2ª. Ed.- Buenos Aires, 1978, p.34. 
IX. La obligación directa o indirecta para obtener artículos de consumo en tienda o lugar determinado;

X. La facultad del patrón de retener el salario por concepto de multa;

XI. Un salario menor que el que se pague a otro trabajador en la misma empresa o establecimiento por trabajo de igual eficiencia, en la misma clase de trabajo o igual jornada, por consideración de edad, sexo o nacionalidad;

XII. Trabajo nocturno industrial o el trabajo después de las veintidós horas, para menores de dieciséis años; y

XIII. Renuncia por parte del trabajador de cualquiera de los derechos o prerrogativas consignados en las normas de trabajo.

En todos estos casos se entenderá que rigen la Ley o las normas supletorias en lugar de las cláusulas nulas.

Artículo $6^{\mathbf{0}}$. - Las Leyes respectivas y los tratados celebrados y aprobados en los términos del artículo 133 de la Constitución serán aplicables a las relaciones de trabajo en todo lo que beneficien al trabajador, a partir de la fecha de la vigencia.

Artículo 17. - A falta de disposición expresa en la Constitución, en esa Ley o en sus Reglamentos, o en los tratados a que se refiere el artículo $6^{\circ}$., se tomarán en consideración sus disposiciones que regulen casos semejantes, los principios generales que deriven de dichos ordenamientos, los principios generales del derecho, los principios generales de justicia social que derivan del artículo 123 de la Constitución, la jurisprudencia, la costumbre y la equidad.

Artículo 18. - En la interpretación de las normas de trabajo se tomarán en consideración sus finalidades señaladas en los artículos $2^{\circ}$. y $3^{\circ}$. En caso de duda, prevalecerá la interpretación más favorable al trabajador.

Artículo 33. - Es nula la renuncia que los trabajadores hagan de los salarios devengados, de las indemnizaciones y demás prestaciones que deriven de los servicios prestados, cualquiera que sea la forma o denominación que se le dé. Todo convenio o liquidación, para ser válido, deberá hacerse por escrito y contener una relación circunstanciada de los hechos que lo motiven y de los derechos comprendidos en él. Será ratificado ante la Junta de Conciliación y Arbitraje, la que lo aprobará siempre que no contenga renuncia de los derechos de los trabajadores. 
En todo caso, relacionado con la naturaleza de orden público que se reconoce a las normas laborales, encontramos las más conocida y unánime expresión del principio de irrenunciabilidad, en aquellas normas conforme a las cuales no solo se admiten las renuncias que los trabajadores formulen a las disposiciones que les favorezcan, sino que en caso de producirse las mismas se reputan como absolutamente nulas. ${ }^{2}$

En ese sentido no solo se declara en la ley laboral que "los derechos sociales adquiridos son irrenunciables", sino que toda renuncia disminución o tergiversación de esos derechos.Una función tutelar inherente al principio de irrenunciabilidad, deviene según ese enunciado como incuestionable.

\section{El principio de continuidad de la relación.}

El principio de la continuidad o la continuación se puede definirse como aquel según el cual también en beneficio del trabajador, se establecen una serie de reglas que definen a las relaciones laborales como dotadas de una "extremada vitalidad y dureza" y que realizan o evidencian" la tendencia del derecho del trabajo por atribuirle la más larga duración a la relación laboral desde todos los puntos de vista y en todos los aspectos". El principio orienta así el anhelo por relaciones labores regidas por un régimen de verdadera estabilidad en el empleo.

Se introduce con ello una restricción importante al mercado laboral, la que resulta admisible solo cuando previamente se ha admitido la abierta y válida intervención del Estado en las relaciones privadas, con el mismo se pretende brindar alguna estabilidad a los trabajadores, obligados a la venta de su fuerza de trabajo como medio de subsistencia. Las manifestaciones concretas del principio referido en el ámbito de la Ley laboral pueden ser expuestas, entre otras maneras expresando que se privilegia y acentúa la existencia de relaciones laborales a tiempo indeterminado, por sobre las relaciones a tiempo determinado. De ello deriva como una regla general que el contrato de trabajo se reputa a tiempo indeterminado y solo excepcionalmente y ante circunstancias muy calificadas admiten las contrataciones a tiempo determinado, ya sean estas a plazo fijo o por obra determinada.

Como consecuencia directa de lo indicado, se han establecidos presunciones especificas en favor de las relaciones a tiempo indefinido o indeterminado, cuando a la finalización persistieran las causas que originaron la contratación, o bien cuando la naturaleza indefinida de la relación derivase de la prestación misma. El principio en examen implica que las relaciones laborales se conciben dentro de un marco de extremada resistencia. Se establecen como simples suspensiones lo que en otros

2 PAlOMinO, Teodosio A. El Derecho del Trabajo en las Constituciones de Iberoamérica. Perú: ed. Juris Laboral, 1999 , p.57. 
ámbitos sería considerado como verdaderas interrupciones de la relación entre los sujetos. Así mismo se produce una restricción importante en materia de las modificaciones unilaterales por parte del patrón a la relación laboral.

Finalmente el principio de continuidad comprende una resistencia a la terminación incausada de las relaciones laborales. Tal y como se indico, según la concepción clásica del principio, se supone que el derecho laboral conduciría hacia el establecimiento en la ley de una garantía de estabilidad en el empleo. Conforme a ello el despido solo sería posible en los casos en que el trabajador incurriera en una falta grave (causal de despido) a sus obligaciones, de lo contrario operaría la reinstalación y la justa indemnización. De esta forma la finalización de las relaciones laborales se reputa como un suceso de alta relevancia para la ley laboral, objeto como tal de una exhaustiva regulación dotada de algunas características particulares.

\section{Principio de la condición más beneficiosa:}

El principio de la condición mas beneficiosa o que mas favorezca es la clara manifestación que como derecho adquirido subsiste; es decir que reúna todos los presupuestos exigidos por la norma para su imputación a favor del sujeto en calidad de prerrogativa jurídica individualizada a las concretas situaciones configuradas en el tiempo a través de la duración de la relación de trabajo, que comporten beneficios posteriores al inicio de aquella, que se adquieren con alcance permanente e intuito persona.

Debe tratarse de condiciones originadas en normas contractuales, expresas o tácitas, de alcance individual, ya que las originadas en contratos colectivos tienen su propio régimen en orden a la vigencia temporal de sus cláusulas. En un nuevo convenio colectivo, dentro de la libertad de negociación puede haber condiciones laborales que mejoran lo existente. En el segundo supuesto al que se arriba por imposición de circunstancias críticas, se opera una regresividad de los beneficios sociales que aunque no sea deseable puede constituir la condición para alcanzar otros objetivos tan valiosos como el de la conservación del empleo entre otros.

\section{Principio de igualdad de trato:}

El principio de igualdad de trato se concreta en que de parte del empleador, el trabajador reciba un tratamiento igual, para iguales en iguales circunstancias. Esa matizada igualdad de trato que no consiste en igualitarismo mecánico, equivale a la prohibición de trato diferente arbitrario. De este principio se configura el respectivo derecho subjetivo a no ser tratado arbitrariamente con desigualdad. 
Por ello se destaca lo que señal la Ley Laboral de referencia de nuestro país:

Artículo 56. - Las condiciones de trabajo en ningún caso podrán ser inferiores a las fijadas en esta Ley y deberán ser proporcionadas a la importancia de los servicios e iguales para trabajos iguales, sin que puedan establecerse diferencias por motivo de raza, nacionalidad, sexo, edad, credo religioso o doctrina política, salvo las modalidades expresamente consignadas en esta Ley.

En concordancia de la legislación en México podemos encontrar en texto constitucional vigente lo siguiente:

Artículo 1.- En los Estados Unidos Mexicanos todo individuo gozará de las garantías que otorga esta Constitución, las cuales no podrán restringirse ni suspenderse, sino en los casos y con las condiciones que ella misma establece.

Está prohibida la esclavitud en los Estados Unidos Mexicanos. Los esclavos del extranjero que entren al territorio nacional alcanzarán, por este solo hecho, su libertad y la protección de las leyes.

Queda prohibida toda discriminación motivada por origen o nacional, el género, la edad, las discapacidades, la condición social, las condiciones de salud, la religión, las opiniones, las preferencias, el estado civil o cualquier otra que atente contra la dignidad humana y tenga por objeto anular o menoscabar étnico los derechos y libertades de las personas.

De tal suerte que también en legislación diversa se destaca lo que determina la Ley Federal para prevenir y eliminar la discriminación;

Artículo 1. - Las disposiciones de esta Ley son de orden público y de interés social. El objeto de la misma es prevenir y eliminar todas las formas de discriminación que se ejerzan contra cualquier persona en los términos del Artículo 1 de la Constitución Política de los Estados Unidos Mexicanos, así como promover la igualdad de oportunidades y de trato.

Artículo 2. - Corresponde al Estado promover las condiciones para que la libertad y la igualdad de las personas sean reales y efectivas. Los poderes públicos federales deberán eliminar aquellos obstáculos que limiten en los hechos su ejercicio e impidan el pleno desarrollo de las personas así como su efectiva participación en la vida política, económica, cultural y social del país y promoverán la participación de las autoridades de los demás órdenes de Gobierno y de los particulares en la eliminación de dichos obstáculos. 


\section{El principio de beneficio en caso de duda:}

En su origen, el principio in dubio pro operario implicó invertir el principio vigente en el derecho privado según el cual los casos dudosos deben resolverse a favor del trabajador La inversión consistió en otorgar un amparo a la parte más débil en el contrato de trabajo; parte más débil que precisamente a consecuencia de su debilidad se encuentra en la mayoría de los casos en la situación de acreedor. Para la aplicación del principio de favor de la duda, entendida ésta como determinación del ánimo entre dos extremos contradictorios, debe ser insuperable. A propósito de sí el principio de in dubio pro operario comprende sólo a la interpretación de las normas o sí también rige en la apreciación de la prueba, es más congruente con el principio protectorio el criterio amplio. Por cierto que no cabe aplicarlo en caso de deficiencia probatoria del trabajador en el onus probando a su cargo sino cuando coexisten pruebas aportadas por ambas partes y acabando su examen cuidadoso quede colocado el juez en incertidumbre sobre la realidad de los hechos.

\section{Principio de la Primacía de la Realidad:}

Este principio apunta a evitar el fraude laboral o la simulación normalmente, que aparecerá en las legislaciones laborales de algunos países latinoamericanos o países de avanzada y objetiva legislación sobre todo una disposición que señale: "Será nulo todo contrato por el cual las partes hayan procedido con simulación o fraude a la ley laboral, sea aparentando normas contractuales no laborales, interposición de personas o de cualquier otro medio".

Es por ello que en caso de discordancia entre lo que surja de documentos o acuerdos escritos y lo que sucedió en la realidad, se prefiere lo último, justamente porque lo que se persigue es la verdad real y no la verdad formal.

De ahí la expresión jurídica de que el contrato laboral es un Contrato Realidad. El contrato laboral depende más de una situación objetiva (cumplimiento de la prestación de servicios) que de una situación subjetiva. El contrato existe no por el mero acuerdo de voluntades sino de la realidad de la prestación por encima de las formas o acuerdos jurídicos a los que las partes hayan llegado. ${ }^{3}$

3 VILLASMIL PRIETO, Humberto y RODRIGUEZ MEJIA, Giovanni. Código de Trabajo de Nicaragua: edición rubricada y concordada con las Normas Internacionales del Trabajo. —San José, Costa Rica: Organización Internacional del Trabajo, 2006, p.89. 


\section{Principio de la Buena Fe:}

El Derecho del Trabajo pretende que la relación laboral se desenvuelva con conductas propias de un buen empleador y de un buen trabajador, con fidelidad, lealtad, veracidad. Este principio debe ser tenido en cuenta para la aplicación de todos los derechos y obligaciones que las partes adquieren como consecuencia del contrato de trabajo. Es un modo de actuar, un estilo de conducta, una forma de proceder ante las mil y una emergencias de la vida cotidiana que no puede encerrarse ni limitarse a la forma de cumplimiento de ciertas obligaciones.

Es importante entonces señalar que en numerosas oportunidades la autoridad laboral debería acudir en estricto apego a sus facultades conferidas acudiría a verificar cuál ha sido el comportamiento de las partes en esa relación laboral, Constituye un elemento fundamental y dirimente que va ligado al principio de equidad, propio de la autoridad laboral y una directriz que servirá para resolver las cuestiones litigiosas que podrían presentarse entre las partes de esa relación.

La relación de trabajo no se limita a unir a dos sujetos para lograr fines meramente económicos, no crea derechos y obligaciones meramente patrimoniales, sino también personales, de una relación basada en el trabajo mismo con una esencia de respeto y orden; ya que tiene como objetivo una actividad productiva y creadora del hombre en sí. Se refiere a la conducta que debe mostrarse al cumplir realmente con su deber, supone una actuación ejecutada en forma honesta y honrada. Es una forma de vida, un estilo de conducta al que las partes están obligadas a someterse.

\section{Principio de la Razonabilidad:}

Por este principio entendemos la afirmación esencial de que el ser humano en sus relaciones laborales, procede y debe proceder conforme a la razón. sentidos:

En el campo del Derecho Laboral la aplicación de este principio actúa en dos

1) Sirve para medir la verosimilitud de determinada explicación o solución. En la inmensidad de situaciones en que una persona se coloca al servicio de otra mediante el pago de una retribución existe una infinidad de situaciones equívocas, confusas: son las famosas zonas grises del Derecho Laboral y se refieren a aquéllas en las que se requieren un estudio para poder determinar si se trata o no de una relación de trabajo. No en pocas ocasiones se trata de disimular al amparo de formas legales las verdaderas relaciones laborales; el criterio de racionalidad puede servir como criterio distintivo en situaciones límites o confusas en las cuales deba distinguirse la realidad de la simulación. Este principio parte del supuesto de que el hombre 
común actúa generalmente conforme a la razón y encuadrado en ciertos patrones de conducta. Las excepciones deben justificarse y probarse especialmente y para descubrir la realidad de las cosas utilizamos los principios que hemos enunciado.

2) También sirve como cauce, como límite, como freno de ciertas facultades cuya amplitud puede prestarse para arbitrariedades. La esencia misma de la relación de trabajo mediante la cual una persona se pone al servicio de otra durante un lapso de tiempo para que ésta le indique las tareas y le determine la forma en que debe actuar, obliga a ciertos límites elásticos y variados que mantengan ese poder de dirección que posee el patrón o empleador dentro de los cauces adecuados.

Este poder de dirección y organización de la Empresa que tiene el empleador frente al trabajador requiere de una discrecionalidad en el actuar de éste, pero en aras de esa discrecionalidad no podría aceptarse la arbitrariedad. El principio de racionalidad tiende a evitar las actuaciones arbitrarias del empleador en la toma de decisiones que involucren el desempeño de las funciones o tareas contratadas con el trabajador.

Es principio tiene gran aplicación en casos de:

- Ius Variandi: que es la posibilidad que tiene el empleador de variar las condiciones de trabajo dependiendo de las necesidades de empresa, pero sin que ello signifique una arbitrariedad, sin que altere las modalidades esenciales del contrato, ni cause un perjuicio material o moral al trabajador, pero fundamentalmente que esos cambios no importen un "ejercicio irrazonable de esa facultad".

- Poder Disciplinario: nadie puede negar el poder disciplinario del empleador, pero la medida correctiva debe ser aplicada en proporcionalidad a la falta cometida, actuando razonablemente. ${ }^{4}$

\section{Principio de gratuidad:}

Es el principio por el cual se le garantiza al trabajador el derecho de defensa a través de la gratuidad de los procedimientos, de modo que dicho derecho no resulte comprometido por el costo económico que podría significar para el dependiente, cuando dicho costo pueda ser una limitación para su ejercicio. Este principio apunta fundamentalmente a que el trabajador tenga acceso a la justicia de manera libre y sin entorpecimiento fiscal, o cualquier otro emolumento que deba afrontar para iniciar ante los tribunales laborales su pretensión.

4 RODRIGUEZ VALENCIA, Joaquin. Administración moderna de personal, editorial Ecasa, Mexico, año 2000,p.53 
En concordancia con una realidad aparente los principios enumerados y significado han sido lo más apropiado, constituyéndose en el fundamento medular propiamente dicho del derecho del trabajo que ha referenciado la orientación de esta hermosa disciplina jurídica del derecho social y humano, el mismo aceptado y reconocido en la estructura de la economía jurídica de; casi todos los países miembros de la Organización Internacional del Trabajo y de las Naciones Unidas. ${ }^{5}$

\section{Los efectos del modelo económico actual y la necesaria revalorización de los principios del derecho laboral y sus normas protectoras:}

En la realidad actual, en que forma el proceso de globalización económica y concretamente la implementación del nuevo modelo de desarrollo, ha generado un replanteamiento o reconsideración de los principios generales del derecho laboral.

El establecimiento de un nuevo modelo de desarrollo se inicia aproximadamente a partir de la década de los 80. Las dificultades económicas de los países en desarrollo como el caso de nuestro país, y un conjunto de factores externo como la globalización económica, obligan al abandono del modelo de sustitución de importaciones pese. Se sitúa a partir de ese momento en un lugar privilegiado, a la ubicación que obtenga la producción de cada país en el mercado internacional, en función de un nuevo modelo basado en las exportaciones y la apertura comercial. La búsqueda de satisfacer esa nueva pretensión lleva a los países a la ejecución de un conjunto de políticas. Entre todas ellas destaca un proceso de ajuste estructural destinado a las transformaciones de las estructuras económicas para integrar las economías a las nuevas tendencias integracionistas y globalizantes que provocaron los Tratados de Libre Comercio. El nuevo orden económico propuesto parte de la regulación de todas las actividades de la sociedad mediante las leyes del mercado, y ello incluye también a las relaciones laborales.

Para el logro de ese cometido, se realizan una serie de medidas que tienen claras repercusiones en el derecho laboral y en otras áreas de la vida de los trabajadores y la sociedad. Entre muchas de esas medidas, como la creación políticas de promoción de las exportaciones, el establecimiento de Zonas Francas de Exportación, la instalación de un conjunto de empresas bajo el sistema de maquila, y la reducción y la información de los aranceles de importación; la reducción y afectación del mercado interno. Lo que se logra a través de salarios decrecientes, la eliminación de subsidios a la producción nacional de granos básicos y a la pequeña empresa, así como mediante la desregulación del mercado de trabajo, la flexibilización laboral y la

RODRIGUEZ VALENCIA, Joaquin. Administración moderna de personal, editorial Ecasa, Mexico, año 2000 , p.53, p.67. 
privatización de los servicios públicos y la reducción del Estado; políticas de apertura comercial. La cual se manifiesta no sólo en un innegable proceso de reducción y uniformación de aranceles, sino también en la conformación de diversos bloques comerciales, destinados a la liberalización del comercio internacional.

El conjunto de todas esas políticas, y algunas otras no mencionadas, como es el caso de la reducción del aparato estatal, evidencias una modificación en ocasiones lenta pero siempre trascendental; que en todo caso revela el establecimiento del indicado nuevo modelo de desarrollo. Si admitimos una estrecha relación entre el modelo de relaciones laborales entendiéndosele como comprensivo del modelo de contratación, el sistema de fijación de salarios, flexibilidad laboral. En este modelo de desarrollo estaremos admitiendo a su vez, la existencia de una serie de requerimientos que surgen precisamente de la modificación apuntada.

Esa relación entre los modelos conlleva un tránsito a un nuevo sistema de producción y de regulación que puede catalogarse como el surgimiento de un nuevo orden emergente; en el cual no sólo resulta evidente un abandono del papel interventor tradicional del Estado en los mercados, sino que en lo que aquí, interesa estaría caracterizado además por una prevalencia de los formas no típicas de contratación, la flexibilidad en las funciones y en el horario, la diversificación de las formas de remuneración, la extensión de la subcontratación o la aparición de nuevas modalidades de contratación como el teletrabajo, el trabajo por resultados o el outsourcing mismo.

En síntesis, de lo apuntado derivarían buena parte de los requerimientos que en función del actual y nuevo modelo de desarrollo estarían obligando a muchos países en vías de desarrollo o consolidación de su economía a satisfacer lo que se requiera. Dado que algunos de esos requerimientos como ya se ha indicado inciden sobre las relaciones laborales, se plantea su vez que los mismos sean satisfechos a través de la modificación de las normas laborales. En el ámbito laboral, como en otros, los requerimientos se justifican en términos generales a partir de la necesidad de obtención de la competitividad en el mercado internacional y tendrían a su vez como sus componentes básicos a la productividad, la calidad y la flexibilidad.

De lo anterior se deriva un claro cuestionamiento de la función tutelar asignada en la teoría y en la ley laboral tradicional como un contenido central de los principios generales del derecho del trabajo. El nuevo modelo económico mundial y regional, plantea una necesaria revisión a los actuales principios del derecho laboral, que permita resolver los grandes fenómenos que la globalización ha producido en el mundo del trabajo y a los trabajadores. 
El fenómeno de la flexibilidad laboral nos plantea una necesidad de atender problemas como la inestabilidad laboral, la falta de protección, entre otros problemas que aquejan a los trabajadores y por consiguiente al derecho del trabajo. Se hace urgente y necesario impulsar reformas profundas a las legislaciones laborales, que profundicen y desarrollen con mayor fuerza estos principios, incorporando procedimientos y técnicas aceptadas y consensuado con los sujetos: trabajadores y empleadores. Un mecanismo importante, necesario e imprescindible, sería buscar a como lo ha planteado una nueva corriente de académicos iberoamericanos que denominó "la constitucionalización de los principios sociales del Derecho del Trabajo", similar a la corriente del constitucionalismo social que incluyó a comienzos del siglo XX, las normas sociales de los trabajadores en diversas constituciones, americanas y de Europa. Esta incorporación de los Principios del Derecho del Trabajo en las normas constitucionales de América Latina sería de vital importancia porque estaría consagrando en el nivel más alto del ordenamiento jurídico tales fines, con el objetivo de preservar el espíritu de dichas normas y evitar que la globalización atente contra su existencia.

\section{La protección en contra de la discriminación laboral:}

Con el desarrollo de una cultura de protección de los derechos humanos, se ha extendido la necesidad de tutelar la vigencia real de la igualdad en diferentes instancias de la vida social. Ha crecido la convicción de que no han sido suficientes las proclamas y declaraciones formales, que arrancaron con la Revolución Francesa y la Revolución Americana, conforme a las cuales todas las personas deben recibir un trato igualitario, tanto en relación con el Estado como en las relaciones entre particulares.

Existe una abundante normativa internacional que contiene disposiciones dirigidas a garantizar la igualdad y excluir la discriminación en diferentes planos de la vida social. Buena parte de esa normativa ha sido ratificada por los países americanos. Pueden mencionarse, además de las adoptadas por la Organización Internacional del Trabajo, las siguientes: Carta de la Organización de los Estados Americanos (1948, con reformas posteriores); Declaración Americana de los Derechos y Deberes del Hombre (1948); Carta Internacional Americana de Garantías Sociales (1948); Declaración Universal de los Derechos Humanos (1948); Convención Americana sobre Derechos Humanos (1969); Convención Internacional sobre la eliminación de todas las formas de discriminación racial (1965); Pacto Internacional de Derechos Civiles y Políticos (1966); Pacto Internacional de Derechos Económicos, Sociales y Culturales, de las Naciones Unidas; Protocolo Facultativo del Pacto Internacional de Derechos Civiles y Políticos; Protocolo Adicional a la Convención Americana sobre 
Derechos Humanos en materia de Derechos Económicos, Sociales y Culturales ("Protocolo de San Salvador", 1988); Convención sobre los Derechos del Niño (1989).

La necesidad de introducir mecanismos que aseguren que en sentido material se respete el valor universal de la igualdad, conduce a la adopción de dispositivos que, a su vez, enfrenten la discriminación, figura que ha perturbado desde siempre la convivencia humana. La experiencia indica que los seres humanos no se convierten en iguales, con la sola afirmación constitucional o legislativa de que lo son. Se colisiona con la igualdad tanto cuando a unos pocos se reconocen beneficios y derechos que, en igualdad de circunstancias, se niegan a los demás (situación que suele calificarse como fuero o privilegio personal); como cuando a una minoría se niegan, de manera ilegítima, beneficios o derechos que se reconocen con carácter general. ${ }^{6}$

Lo último da lugar a la discriminación. La diferencia entre el fuero o privilegio y la discriminación es hasta cierto punto cuantitativa, pero en ambas situaciones se vulnera el valor de la igualdad. Por mucho tiempo, aún con sistemas formalmente democráticos, incluso considerados por muchos como paradigmas de democracia.

En todo caso, la extensión de las preocupaciones por la erradicación de la discriminación, ha conducido a la puesta en vigencia de sistemas de protección dirigidos hacia sectores o personas en situación de vulnerabilidad ante eventuales acciones o actitudes de diferenciaciones ilegítimas. Superadas básicamente las anteriores formas de discriminación, subsiste, como en todas partes, el viejo dilema de cómo erradicarla materialmente, más allá de las proclamas formales. Esta tendencia irrumpió más allá de los aspectos tradicionalmente considerados de discriminación (edad, sexo, raza, condición social o económica, ideas políticas o religiosas.), para adentrarse en situaciones nuevas, como orientación sexual, apariencia física, portadores del VIH y discapacitados laborales por diversas razones, entre ellas las de enfermedades crónicas, involutivas o degenerativas.

En todo caso, debe tenerse claro que la idea de la igualdad no excluye la posibilidad de tratos diferenciados, cuando existen razones legítimas para hacerlo, aspecto que cobra especial significación en el terreno de de los derechos sociales, que apuntan hacia un concepto distributivo de la justicia. Trato diferente o determinadas ventajas legítimamente reconocidas respecto de personas que se encuentran en situaciones diversas, no implican necesariamente actos de discriminación.

6 Cuando una minoría impone un régimen de negación de derechos fundamentales a la mayoría (por ejemplo el apartheid en Sudáfrica), en general se ha visto como un sistema discriminatorio, aunque, en el fondo, se trata de dotar a la minoría de un conjunto de privilegios. 
En ese orden de ideas se pertinente señalar que lo que hacía descansar la discriminación en la afectación arbitraria e injustificada de la igualdad, de modo que la discriminación se daría "cuando, arbitrariamente, se efectúa una distinción, exclusión o restricción que afecta el derecho igualitario que tiene toda persona a la protección de las leyes, así como cuando injustificadamente, se le afecta a una persona, o grupo de personas o a una comunidad el ejercicio de alguna de las libertades fundamentales". 7

\section{La protección social internacional en contra de la discriminación en el derecho del trabajo:}

En el derecho del trabajo, en el cual una de sus fundamentales separaciones del derecho común radica en que enfoca la igualdad (y también la libertad) desde un punto de vista material y no puramente formal, este tema cobra particular trascendencia. El enfoque material de la igualdad, así como condujo a la figura del contratante jurídicamente protegido, provocó también la incorporación de dispositivos antidiscriminatorios, como la igualdad de salario, la de trato y la de condiciones de trabajo, la protección de la actividad sindical en sus más amplias manifestaciones y, en general, la protección en contra del despido discriminatorio.

Particular valor ha dado la Organización Internacional del Trabajo al tema de la igualdad y no discriminación. Se expresa, de manera general, en la Constitución de la OIT, en la Declaración de Filadelfia y en la Declaración relativa a los principios y derechos fundamentales en el trabajo. Igualmente, se incluye entre sus ocho convenios fundamentales, en los Convenios 100 (Igualdad de remuneración entre la mano de obra masculina y la mano de obra femenina por un trabajo de igual valor) y 111 (Discriminación empleo y organización), a los cuales se agregan todos los relativos a la protección de la libertad sindical en su conjunto, en especial los Convenios 87 y 98, que están también entre los ocho convenios fundamentales de la OIT.

Para la OIT la discriminación en el trabajo comprende todo trato diferenciado y menos favorable de determinadas personas en razón de situaciones como raza, color, sexo, religión, opinión política, ascendencia nacional u origen social, en los términos del Convenio 111; o, según las nuevas tendencias, discapacidad, edad, estado de salud, afiliación sindical o situación familiar, "sin perjuicio de su capacidad para cumplir los requisitos correspondientes al puesto de trabajo". ${ }^{8}$

MARTINEZ VIVOT, Julio, La discriminación laboral - despido discriminatorio, Ciudad Argentina, Universidad del Salvador, Buenos Aires, 2000, p. 27.

8 Oficina Internacional del Trabajo, La igualdad en el trabajo: afrontar los retos que se plantean, Informe I (B), $96^{a}$ reunión, Ginebra, 2007, p. 9. 
Las exigencias de igualdad llevan a la OIT a considerar como una forma de discriminación indirecta, "el trato diferenciado de algunas categorías específicas de trabajadores traducida en menores prestaciones o remuneraciones". A propósito, cita, como ejemplo de esta forma de discriminación indirecta la protección jurídica inferior que en todo el mundo tienen los trabajadores domésticos, que son principalmente mujeres mal retribuidas, pertenecientes a minorías étnicas o raciales y con frecuencia extranjeras. ${ }^{9}$

En la mayoría de las legislaciones en países latinoamericanos sobre todo; que reconocen el libre despido, suelen señalarse excepciones que vendrían a configurar una suerte de estabilidad temporal, la vulneración de la cual abriría, en varias legislaciones, la posibilidad de nulidad del despido. Entre estos supuestos, están los sistemas de protección especial generalmente conocidos como fueros, que, con diversas variantes, se dirigen a excluir de manera temporal el poder patronal de libre despido y, la mayoría de las veces, a disponer restricciones de forma o de procedimiento previo al mismo despido justificado. Tales modalidades especiales de protección también se regulan en los sistemas que reconocen la estabilidad en el empleo.

Dentro de las motivaciones discriminatorias pueden entrar muchas históricamente tradicionales, al igual que nuevas figuras que se estiman tienen esa connotación. Así, pueden mencionarse, los despidos motivados por el embarazo, el matrimonio reciente, la actividad o representación sindical, represalias por el ejercicio de derechos laborales o de la seguridad social, por resistencia al acoso sexual, actividad política, discapacidad, ser portador de VIH, raza, sexo, orientación sexual, situación familiar, opinión, idioma, nacionalidad, origen nacional, condición social o económica, edad, religión, ideas políticas. El tema resulta más abarcador en tanto no se trata sólo de la tutela de los derechos fundamentales de los trabajadores como tales, sino, igualmente, de la tutela de los derechos del trabajador en su condición de persona o ciudadano, que no pueden ser desconocidos en la empresa, por el poder jurídico ejercido por el empleador.

\section{Trascendencia del tema de la igualdad de género:}

Con la fuerte irrupción de las corrientes igualitarias de la mujer respecto del hombre y de rechazo a las diversas manifestaciones de la discriminación de género, se ha producido una extendida normativa en esa dirección, tendiente a rebasar las anteriores declaraciones formales, para dar paso a mecanismos concretos de

9 Oficina Internacional del Trabajo, La igualdad en el trabajo: afrontar los retos que se plantean, Informe I (B), 96a reunión, Ginebra, 2007, p. 10. 
aseguramiento efectivo de la igualdad. Es de resaltar que el potenciado tema de la igualdad de género, se enlaza hoy con la extensión de lo que se consideran como condiciones susceptibles de discriminación.

Paralelo a este fenómeno, en la realidad de la sociedad y en el escenario laboral es visible y sostenida la incorporación de la mujer a todos los oficios y profesiones, incluidas las posiciones técnicas y de mando. En muchos lugares $-\mathrm{y}$ todavía hoy- la presencia femenina en el trabajo, provocó reacciones de rechazo, que rebasaron el histórico comportamiento machista del acoso sexual, para dar lugar a variantes más bien de acoso sexista, con el cual antes que favores sexuales lo que se pretende es la salida de la mujer del puesto de trabajo. Estas variantes pueden llegar a manifestaciones propias del acoso moral.

Este tema se enlaza con factores culturales que por largo tiempo condujeron a que ciertas profesiones fueran consideradas como típicamente masculinas o, a la inversa, como propias de las mujeres (por ejemplo: enfermería, secretarias, trabajo doméstico).

Este fenómeno social de igualación de género se enlaza con la incorporación, antes anotada, de nuevos elementos antidiscriminatorios. Es, en fin, un estadio en el cual la Humanidad, rescata y profundiza el valor de la igualdad y el rechazo de la discriminación, con la inclusión en ese rechazo de antiguos y nuevos criterios de no discriminación.

La profundización del tema de la igualdad de género, visto desde la perspectiva material de la posición de la mujer, lleva hoy a que, de manera inversa, algunos cuestionen si no sería discriminación de género en contra de los hombres, ciertas diferenciaciones en el mínimo de cuotas electorales o en ciertas reglas de protección de la seguridad social (edad para pensionarse, pensión de viudez).

Parte de la importancia de las caracterizaciones normativas actuales, es que no se trata sólo de dispositivos prohibitivos de la discriminación, sino también de establecer mecanismos efectivos de equiparación laboral.

\section{La protección de los derechos sindicales:}

Debe destacarse igualmente, el peso de criterios relativos a la protección contra la discriminación antisindical, sistematizados en principios generales, actos de discriminación, dirigentes y delegados sindicales, necesidad de protección rápida y eficaz, reintegro de sindicalistas en sus puestos de trabajo y discriminación en perjuicio de los empleadores. ${ }^{10}$

10 Oficina Internacional del Trabajo, La libertad sindical, cuarta edición, Ginebra, 1996, pp. 151-163. 
Entre las mencionadas modalidades están las que protegen la maternidad, la representación o actividad sindical o de representación de los trabajadores, a los trabajadores en situación de conflicto colectivo o de arbitraje, incapacitados, portadores de VIH, a los que están en uso de vacaciones o bajo suspensión de los efectos de la relación de trabajo, en situación de pre-jubilación, discapacitados laborales, trabajadores con cargas familiares, trabajadores con reclamaciones recientes de carácter laboral o de seguridad social.

Por otro lado, los actos de discriminación, fundados en ilegítimas diferenciaciones, entre ellas las de carácter antisindical, pueden comprender situaciones como las siguientes: ofertas de empleo con requisitos discriminatorios; criterios de selección de personal, fundados en elementos discriminatorios; afectación indebida de la igualdad de salario; restricciones discriminatorias en los programas de capacitación; diferenciaciones discriminatorias en la determinación de promociones, renovación de contratos, movilidad en el empleo y ascensos; determinación de las características de las tareas y de las condiciones materiales y tecnológicas del trabajo, mediante la utilización de criterios discriminatorios; utilización de criterios discriminatorios en la aplicación de medidas disciplinarias; utilización de criterios discriminatorios en la determinación de la reducción de personal; Realización de actos de acoso sexual.

Fundar el despido en consideraciones discriminatorias o que el mismo obedezca materialmente a tales consideraciones, independientemente de la identificación formal de una justa causa de despido.

La asociación sindical, también como conocida como asociación profesional y para algunos autores como sindicato, difiere de la asociación general definida en el derecho civil, en última instancia es la asociación de trabajadores que de manera permanente se unen con la intención de defender sus derechos; esta es la parte que marca la diferencia con la asociación en general; el sindicato es la unión de trabajadores, cuyo único objetivo es la defensa de sus intereses laborales, y no de ninguna otra índole.

(...) la libertad general de asociación es uno de los derechos individuales del hombre, en tanto la libertad sindical es un derecho de clase, cuyo objetivo primero es igualar la fuerza de trabajo y la del capital y lograr para los trabajadores condiciones dignas en la prestación de los servicios............ $)^{11}$.

Acerca del concepto en sí de la libertad sindical señala que la trilogía indisociable, a saber, el derecho de asociación, el de negociación colectiva y el de huelga.

11 Oficina Internacional del Trabajo, La libertad sindical, cuarta edición, Ginebra, 1996, pp. 151-163. 
La libertad sindical es así una manifestación de la libertad individual,"es un complemento de la libertad individual de los trabajadores". En ejercicio de ella se llega a la creación de un grupo, que tiene una personalidad distinta de las personas que han contribuido a su constitución; los principios que derivan de la libertad sindical, de acuerdo con la OIT son:

a) Derecho de constituir organizaciones sindicales.Ello significa que los trabajadores y empleadores pueden crearlas sin distinción de ninguna clase, sin autorización previa y ser organizaciones de su elección.

b) Derecho de afiliarse a estas organizaciones.

c) Garantías al derecho de libertad sindical.

1. La abstención de las autoridades públicas.

2. Facultad de elaborar sus estatutos y reglamentos administrativos.

3. Elegir libremente a sus representantes.

4. Organizar su gestión y actividad.

5. Formular su programa de acción.

6. No estar sujetos a disolución o suspensión por vía administrativa.

7. Constituir federaciones y confederaciones

8. Constituir organizaciones internacionales o afiliarse a ellas.

9. Proteger a los miembros de un sindicato contra cualquier perjuicio en razón de su afiliación sindical o de sus actividades.

10. Impedir toda injerencia de organizaciones extrañas y;

11. La instauración de medidas para promover y desarrollar la negociación colectiva. 


\section{Autonomía Sindical:}

En caso de los sindicatos el sentido de la autonomía es la voluntad libre y espontánea ejercida por los trabajadores para formar un sindicato, elaborar sus estatutos y otras facultades. Constituirse, redactar estatutos y reglamentos administrativos son los primeros actos democráticos de un sindicato. También debiera serlo elegir libremente a sus representantes. En cuanto a la acción sindical externa, podemos mencionar la participación que éstos tienen en la vida pública de cada país. Los problemas nacionales no pueden ni deben ser ajenos a la clase trabajadora. En algunos casos la acción sindical externa influye en el ánimo de los gobiernos, sobre todo del poder legislativo, para que esas aspiraciones queden plasmadas en el derecho positivo.

Una de las situaciones que colocan a los trabajadores en condiciones de mayor vulnerabilidad a la discriminación, son las relativas a la actividad sindical en sus diferentes manifestaciones. El trabajador puede ser susceptible de acciones patronales en su contra, por razón de su pertenencia o intención de pertenecer a una organización sindical; participar en su formación; dar apoyo en un conflicto colectivo; participar de una huelga o apoyarla; fungir de directivo o representante sindical, esto último tanto en el ámbito de la empresa como en instancias oficiales, bipartitas, tripartitas, de concertación. Situaciones como las que se mencionan en el párrafo anterior, pueden provocar reacciones del empleador que comprometan el ejercicio material de la libertad sindical y del derecho de negociación colectiva. Del mismo modo, en el ejercicio de sus poderes el empleador puede hacer diferenciaciones ilegítimas o mal intencionadas, con el afán de afectar la libertad sindical, mediante el debilitamiento de la estructura sindical con medidas aplicadas discriminatoriamente a los militantes, activistas o dirigentes sindicales.

\section{Los principios del derecho procesal del trabajo en la legislación mexicana:}

Considerando el marco teórico y legal existente, los convenios de la OIT, así como el Pacto Internacional de Derechos Económicos, Sociales y Culturales y otras normas internacionales, nuestro país adopta en su legislación normas de protección social, en especial en la regulación procesal de la relación laboral, y lo concerniente a los principios del derecho del trabajo se observa las disposiciones legales siguientes:

En cambio los principios de razonabilidad y de buena fé, por la naturaleza del trabajo humano esencia del derecho del trabajo, forma parte del contrato de trabajo como obligación del trabajador y el empleador en los objetivos de la relación laboral, y la razonabilidad, la facultad del operador del órgano jurisdiccional, considerar la situación que se le presenta con justificación razonable al momento 
de la aplicación de la justicia; conforme lo estipulado el alcance del procedimiento laboral para las normas adjetivas, en la aplicación de las normas sustantivas en caso de controversia de cuestiones laborales, en concordancia con los principios, Todos los procedimientos y trámites se basarán en los siguientes principios:

a) Gratuidad, por el que todas las actuaciones en los juicios y trámites del trabajo serán absolutamente gratuitas.

b) Inmediación, por el que es obligatoria la presencia del juzgador en la celebración de las audiencias, la práctica de las pruebas y otros trámites.

c) Publicidad, por el que las actuaciones y trámites del trabajo serán eminentemente públicos, es decir, que a ellos pueden asistir todos los que libremente así lo deseen.

d) Impulsor de oficio, por el que los juzgadores tienen la obligación de instar a las partes a realizar los actos procesales bajo conminación de seguir adelante en caso de omisión.

e) Preclusión, por el que el juez, no cumplido por la parte un acto procesal, dentro del tiempo conferido por la Ley, determina la clausura de la etapa procesal respectiva.

f) La lealtad procesal, por la que las partes ejerciten en el proceso una actividad exenta de dolo o mala fe.

g) Proteccionismo, por el que los procedimientos laborales busquen la protección y la tutela de los derechos de los trabajadores.

h) Inversión de la prueba, por el que la carga de la prueba corresponde al empleador.

i) Concentración, por la que se evita la diseminación del procedimiento en actuaciones separadas.

j) Libre apreciación de la prueba, por la que el juez valora las pruebas con amplio margen de libertad conforme a la sana lógica, los dictados de su conciencia y los principios enunciados. 


\section{Derecho a la seguridad social:}

No es posible dejar de mencionar que en 1917, en México se promulgo la primera constitución social del mundo, en la cual se trato se salvaguardar los derechos de los grupos socialmente desprotegidos, en el cual destaca el articulo 123 , que se trata de un especie de contrato social y laboral que ha sido seguida por muchos países de Latinoamérica, resaltando el paternalismo del estado se hace notar también el articulo 39 del mismo ordenamiento jurídico. En el que se establece como un Estado "Benefactor" o estado de "Providencia" que se basa en el principio jurídico fundamental, de que todo ser humano, por el simple hecho de serlo y aun mas por formar parte de una sociedad organizada, tiene derecho a participar de os beneficios del bien común o colectivos y que corresponde a los órganos del Estado intervenir decisivamente sobre las base de sus respectivas atribuciones, a fin de proveer los medios adecuados para satisfacer a plenitud ese derecho humano y social, para beneficiar al pueblo, que es el único soberano en un país democrático.

Pero más allá de los ordenamientos jurídicos y legales de cada país, tenemos que desde 1948 "La Declaración universal de los Derechos Humanos de la ONU" reconoce que el toda persona como miembro de una sociedad tiene derecho a la seguridad social tal como le estable en su artículos 22 y 25 que establecen:

Articulo 22. - "Toda persona, como miembro de la sociedad, tiene derecho a la seguridad social y a obtener, mediante el esfuerzo nacional y la cooperación internacional, habida cuenta de la organización y los recursos de cada Estado, la satisfacción de los derechos económicos, sociales y culturales, indispensables a su dignidad y al libre desarrollo de su personalidad."

Articulo 25. - "Todos tenemos derecho a un nivel de vida adecuado, que asegure a nosotros y a nuestra familia la salud, el bienestar y, en especial, la alimentación, el vestido, la vivienda, la asistencia médica y los servicios sociales necesarios. Tenemos, asimismo, derecho a seguro de desempleo, enfermedad, invalidez, viudez, vejes, u otros casos de pérdida de nuestros medios de subsistencia por circunstancias ajenas a nuestra voluntad." 12

Según la definición del artículo 22., la seguridad social debe cubrir al individuo contra todos los riesgos a que se expone en la vida y en el trabajo.

Pero, el concepto clásico, basado en la solidaridad, universalidad, igualdad, suficiencia y participación, hizo que la seguridad social se convirtiera en un Derecho Humano.

12 "Declaración universal de los Derechos Humanos" Organización de las Naciones Unidas. Texto original aprobado por la Asamblea General. 10 de diciembre 1948.p.4. 
Por lo tanto, un derecho humano que debe ser disfrutado por todos y todas, en todos los sectores (incluyendo obviamente los trabajadores informes y los trabajadores migrantes). En cualquier debate sobre los cambios que hay que hacer (o no) debe partirse de la premisa de la seguridad social es un derecho humano y, por tanto, universal. Sus políticas deben ser incluyentes y participativas.

Cualquier sistema que no cumpla con todos los requisitos señalados es deficiente y debe ser mejorado. Ahora bien según declaraciones de la OIT, ningún país del orbe, incluso los países más desarrollados se ha logrado cumplir a cabalidad estos lineamientos de la seguridad social como un derecho humano universal tan es así que declara lo siguiente:

\begin{abstract}
"Sería ideal que la seguridad social protegiera a todos los miembros de la comunidad, cualquiera que fuera su situación individual en la vida, dicha protección expresaría la solidaridad de la comunidad considerada como un todo, y por supuesto, este concepto subyace en toda la idea de seguridad social. También sería ideal que la protección fuese uniforme en toda la comunidad. Sin embargo, lo ideal no siempre es práctico, e incluso los países con formas más avanzadas de protección social no pretenden que todos los ciudadanos tengan una cobertura completa y adecuada. Además, las condiciones y los estilos de vida cambian, y lo que se consideraba adecuado y justo hace 20 años puede no ser apropiado hoy en día. Por razones de historia, cultura, religión y tradición, a ciertos programas se les puede dar más énfasis que a otros. Las condiciones políticas y económicas tienen también que ser consideradas a la hora de adoptar decisiones acerca de cuáles son los regímenes que se adecuan a las circunstancias". ${ }^{13}$
\end{abstract}

Por lo anterior y atendiendo a la creciente crisis en los sistemas de seguridad social, es que el tema se ha vuelto un tema central en la agenda y en el análisis de diferentes organismos mundiales, regionales y de casi todos los países en las diferentes regiones del planeta. Esto se debe a la importancia que estos sistemas tienen para las economías, sobre todo por los recursos que manejan y también a los problemas que se han ido presentando en la gestión, cobertura y desempeño de la seguridad social.

Sin embargo, la OIT hace una serie de recomendaciones para la reforma de los sistemas seguridad social, para América Latina, para tratar de alcanzar los objetivos de la seguridad social con una cobertura integral y universal. Extender la cobertura de la seguridad social a la mayoría de la población. Los convenios de la OIT prevén que las personas protegidas deberán comprender, al 75\% de la

13 Colección de manuales producidos por el Departamento de Seguridad Social de la OIT. Manual 1. "Principios de la seguridad social, Centro Internacional de Formación de la OIT. Turín. 2001. 
población económicamente activa, o a todos los residentes, señalando que todas las regulaciones jurídicas de los países nacionales consagran el derecho de acceso a la seguridad social para toda la población.

Otorgar prestaciones que respondan a la necesidad del trabajador asegurado y su familia en caso de necesidad de sustituir sus ingresos por invalidez, vejez o muerte o hacer frente a gastos extraordinarios con motivo de la crianza de los hijos o enfermedades. Los convenios de la OIT establecen que los pagos periódicos para el trabajador tipo tienen que ser del orden del $45 \%$ y el $50 \%$ de las ganancias anteriores, revisables con el nivel de ganancias y el costo de la vida. Cabe destacar que la propuesta de porcentajes es en un nivel básico de cobertura que pretende al menos llegue a esos niveles. Contar con un régimen económico-financiero con equilibrio permanente, que no afecte negativamente a la economía nacional ni a las unidades productiva, se menciona el tema de la administración de los fondos, ya que, frecuentemente la acumulación de los fondos colectivos de pensiones en los primeros años de funcionamiento genero la tentación del uso directo para otros fines o a la afectación para otros regímenes de seguridad social, lo que distorsionó la estructura de las prestaciones., además también se refiera a revisar el peso de la carga social sobre los salarios, y si es soportable por las empresas.

Adaptar los regímenes vigentes a las condiciones cambiantes de la vida en sociedad, y muy especialmente utilizarlos como herramientas para lograr metas de cohesión y desarrollo social, en una región donde la integración social y el desarrollo sostenido son un imperativo. Dentro de estos cambios se destaca la reducción del apoyo familiar con que pueden contar las personas de edad avanzada, la situación de la mujer en la vida profesional, que entre otros factores, obligan a instaurar regímenes de protección social que atiendan estas problemáticas. Adaptar los regímenes de jubilaciones y pensiones al mercado de trabajo, sus métodos de contratación, relaciones laborales. Condiciones de trabajo y remuneraciones. El cambiante mercado de trabajo con sus fenómenos de tercerización, movilidad flexibilidad, modalidades de trabajo a tiempo parcial y a domicilio, entre otros fenómenos obliga a adaptar los regímenes de jubilaciones y pensiones.

Introducir modificaciones en la función del estado que se está redefiniendo, con atribuciones, obligaciones y recursos totalmente diferentes al pasado, y en general con menor tamaño. Y esto no se debe entender el privatizar la función del estado si no de encontrar niveles de complementación de funciones para el desarrollo económico-social. Asumir el desafío que presenta la transición demográfica nacional, con mayor impacto en algunos países que en otros, pero que se avizora claramente en el futuro de la región. Ese desafío debe asumirse como una realidad y no como un problema, no solo tiene relación con el equilibrio demográfico y su proyección para el futuro variable con incidencia siempre directa, 
con regímenes colectivos e individuales, sino también se relaciona con la situación del mercado de trabajo y el empleo que condiciono las reformas en las edades de retiro de la fuerza de laboral.

Vincular y armonizar las reformas de los regímenes jubilatorios y pensiones a las reformas de otros regímenes como el de salud, riesgos de trabajo desempleo y asignaciones familiares, Es evidente que no pueden plantearse soluciones a los riesgos de vejez, invalides y muerte, sin mirar al ser humano y a la familia como el centro del problema. Los regímenes de jubilaciones, pensiones y prestaciones sociales no pueden dejar de revisarse. Los sistemas de seguridad social en todo el mundo y en especial en los países en vías de desarrollo se encuentran en una crisis económica y de administración. Ningún, país en el mundo cumple a cabalidad con el principio de universalización de la seguridad social. Desgraciadamente la mayor parte de la población no cuenta con la cultura previsional, y no tiene conciencia, de la importancia de la seguridad social hasta que necesitan de ella.

Dado lo complejo de esta problemática y las distintas situaciones económicas políticas y sociales de cada país sería sumamente irresponsable proponer una solución mágica a esta problemática o una reforma especifica que resolviera la crisis de los sistemas de seguridad social de cada estado. Crear conciencia, y tomar acciones, para que en la medida de las posibilidades de cada país y tomando en cuenta su historia, idiosincrasia, costumbres, situación económica política y social se reformen los sistemas de seguridad social internos.

\section{Conclusiones:}

1. Sin discusión alguna el hecho de humanizarse el trabajo se constituye en un derecho de la sociedad organizada, constituyendo en consecuencia, el bien jurídico protegido "la sobrevivencia humana", porque el trabajo y el salario es base de la convivencia social y desarrollo de la humanidad.

2. En el marco de los grandes acontecimientos económicos y sociales que han enfrentado a la humanidad con el avance industrial, tecnológico y comunicacional, se llega a la conclusión de que el trabajo del hombre es insustituible, si bien el trabajo físico de alguna manera ha sido sustituido, sin embargo el trabajo intelectual jamás desaparecerá.

3. Se observa que el influjo de una política económica universal de liberación de la economía, el mercado y la globalización, han pretendido miminizar el trabajo humano en beneficio de intereses económicos a costa del ultraje a os derechos humanos, retrocediendo la historia ya superada, de aspirar que el trabajo humano ingrese al libre mercado. 
4. Se coincide que los principios postulados por los tratadistas y reflejado en las legislaciones nacionales, han significado la interpretación más correcta del derecho social, y de alguna forma, el manto de protección de los derechos de los trabajadores en el marco del derecho internacional del trabajo y la paz social.

5. En ese contexto se considera que los principios del derecho del trabajo deben reafirmarse y revalorizarse, tomando en cuenta las nuevas formas de trabajo que esta enfrentando la persona humana como consecuencia del desarrollo tecnológico, informático y la presión del mercado con la competitividad (donde el trabajador confronta presión psicológica, física o intelectual) trabajo a distancia por comunicación, salario por hora o producto, extinción de la dependencia o subordinación, horario de trabajo, legislación entre país, seguridad social y beneficios complementarios, por ello amerita la revalorización de los principios.

6. Toda persona como miembro de una sociedad tiene derecho a la seguridad, lo cual se reconoce como un derecho humano en "La Declaración universal de los Derechos Humanos de la ONU" El Estado, tiene la responsabilidad de procurar, suministrar y administrar la seguridad social a todos sus habitantes.

La responsabilidad del Estado de otorgar seguridad social, resulta difícil de cumplir por el alto costo económico que esto representa, mas para los países pobres, por lo cual, un índice muy alto de la población no cuenta con ningún tipo de seguridad social. Por el simple hecho de vivir dentro de una sociedad, y por ser un derecho humano todos los habitantes del estado deberían de contar con seguridad social.

\section{Referencias}

MARTINEZ, Julio, La discriminación laboral - despido discriminatorio, Ciudad Argentina, Universidad del Salvador, Buenos Aires, 2000.

PLÁ, A., Los principios del derecho del trabajo. 2ª Ed.- Buenos Aires, 1978

PALOMINO, T., E1 Derecho del Trabajo en las Constituciones de Iberoamérica. Perú: ed. Juris Laboral, 1999.

RODRIGUEZ, J., Administración moderna de personal, Editorial Ecasa, México, año 2000.

VILLASMIL, H y RODRIGUEZ G. Normas Internacionales del Trabajo. San José, Costa Rica: Organización Internacional del Trabajo, 2006.

OFICINA INTERNACIOL DEL TRABAJO, La igualdad en el trabajo: afrontar los retos que se plantean, Informe I (B), 96ª reunión, Ginebra, 2007. 
COLECCIÓN DE MANUALES PRODUCIDOS POR EL DEPARTAMENTO DE SEGURIDAD SOCIAL DE LA OIT. Manual 1. "Principios de la seguridad social, Centro Internacional de Formación de la OIT. Turín. 2001.

Declaración universal de los Derechos Humanos Organización de las Naciones Unidas. Texto original aprobado por la Asamblea General. 10 de diciembre 1948.

Constitución Política de los Estados Unidos Mexicanos. 2010.

Ley Federal del Trabajo. Editorial Mc Graw Hill.2010.

Ley Federal para prevenir y eliminar la discriminación. 2010

\section{Julio Ismael Camacho Solís}

Doctor en Derecho Público. Catedrático de tiempo completo de la Facultad de Contaduria y Administración Campus I de la Universidad Autónoma de Chiapas. Miembro del Sistema Nacional de Investigadores y del Sistema Estatal de Investigadores del COCYTECH-CHIAPAS. Presidente de la Delegación Chiapas de la Academia Mexicana de Derecho del Trabajo y de la Previsión Social. Presidente de la Academia de Derecho de la Facultad de Contaduría y Administración C-I de la UNACH. 